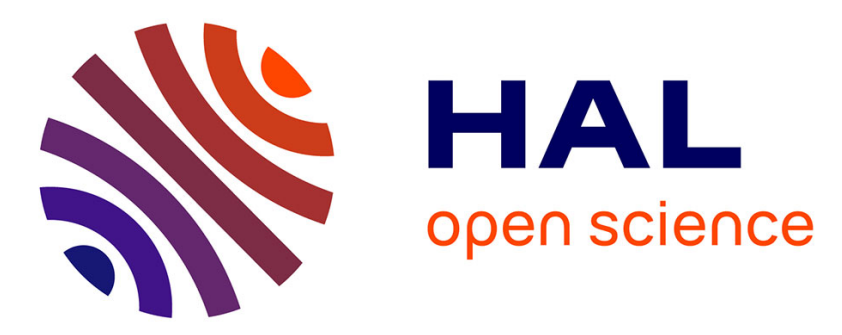

\title{
A propos de l'héritage culturel de la Route de la Soie et de la création d'une " Croix-Rouge" du patrimoine (information)
}

\author{
Ikuo Hirayama
}

\section{- To cite this version:}

Ikuo Hirayama. A propos de l'héritage culturel de la Route de la Soie et de la création d'une " CroixRouge " du patrimoine (information). Comptes-rendus des séances de l'Académie des inscriptions et belles-lettres, 1999, 143 (4), pp.1135-1140. 10.3406/crai.1999.16070 . hal-03587236

\author{
HAL Id: hal-03587236 \\ https://hal.science/hal-03587236
}

Submitted on 24 Feb 2022

HAL is a multi-disciplinary open access archive for the deposit and dissemination of scientific research documents, whether they are published or not. The documents may come from teaching and research institutions in France or abroad, or from public or private research centers.
L'archive ouverte pluridisciplinaire HAL, est destinée au dépôt et à la diffusion de documents scientifiques de niveau recherche, publiés ou non, émanant des établissements d'enseignement et de recherche français ou étrangers, des laboratoires publics ou privés. 


\section{A propos de l'héritage culturel de la Route de la Soie et de la} création d'une « Croix-Rouge » du patrimoine (information) Monsieur Ikuo Hirayama

\section{Citer ce document / Cite this document :}

Hirayama Ikuo. A propos de l'héritage culturel de la Route de la Soie et de la création d'une « Croix-Rouge » du patrimoine (information). In: Comptes rendus des séances de l'Académie des Inscriptions et Belles-Lettres, 143 année, N. 4, 1999. pp. 1135-1140;

doi : https://doi.org/10.3406/crai.1999.16070

https://www.persee.fr/doc/crai_0065-0536_1999_num_143_4_16070

Fichier pdf généré le 21/05/2018 


\section{NOTE DTINFORMATION}

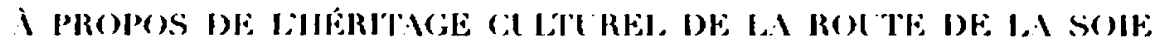

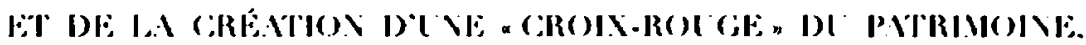

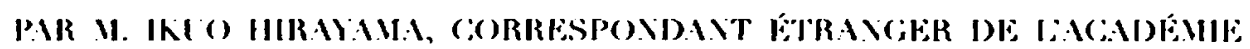

Au cours de ces trente dernières années, je me suis rendu plus d'une centaine de fois sur les sites historiques de la Route de la Soie et j'y ai réalisé de nombreuses peintures. Je voudrais tout. d'abord vous expliquer comment m'est venue cette passion pour la Roule de la Soie.

I ce 6 août 1945, j’ai été victime de la bombe atomique à Iliroshima et j'ai frôlé la mort. A la fin de la Seconde Guerre mondiale, j'étais en effet en troisième année de collège et j'avais été mobilisé pour travailler dans une usine d'armement. C'est là que j’ai subi l'expérience de la bombe atomique. Deux cent un de mes camarades de college et professeurs furent tués sur le coup.

J'ai été miraculeusement sauvé mais, pendant de longues années, j'ai souffert des conséquences de l'irradiation atomique. En 1947, je suis entré dans la section de peinture japonaise traditionnelle de l'F́cole des Beaux-Arts de Tôkyô et j’ai commencé ma carrière artistique. Mais, vers 1959 , j'ai été victime d'une leucopénie et ma vie fut en grave danger. J'ai beaucoup réfléchi el c'est en me fondant sur cette expérience que j’ai réalisé une ceuvre intitulée L'introduction du bouddhisme, dont le thème est une prière pour la paix, comme pour faire la catharsis du traumatisme de ce que: j'avais vécu à Hiroshima. Cette peinture représente, de manièrè à la fois littéraire et inaginaire, le rude voyage entrepris jusqu'en Inde par le: moine chinois Xuanzang de l'époque des Tang, pour y recueillir les textes sacrés et les enseignements du bouddhisme. Par chance, ma santé s’est ensuite améliorée el j’aj pu me lancer véritablement dans la carrière artistique. Au cours des années soixante, j’ai continué de peindre des ceuvres à parlir cle mon interprélation personnelle des thèmes bouddhiques

En 1962 et 1963 , j’ai pu venir étudier en Europe grâce à unc bourse de l'L NESCO. J'ai mené une "F́tude comparée de la peinlure religieuse en Orient et en Occident ", principalement en Italie et en France. Je suis encore aujourd'hui reconnaissant d'avoir eu ainsi la chance, dans ma jeunesse, de vivre quelque temps à 
l'étranger, car cela a constitué une base pour ma formation de peintre. En 1966, j'ai passé quatre mois dans la région de Cappadoce en Turquie, pour participer à une mission d'étude des peintures pariétales de grottes-monastères de l'époque byzantine. I a découverte de ces falaises désertiques et cette expérience de la vie dans le désert a constitué comme un premier pas vers ma rencontre plus tardive des déserts de la Route de la Soie. A partir de 1967, je me suis rendu chaque année sur les sites de la Route de la Soie - cet axe de communication qui a permis les échanges entre les cultures de l'Occident et celles de l'Orient *, que ce soit au Moyen-Orient, en Asie occidentale, en $\Lambda$ sie centrale, en Inde, en Asie du Sud-Est ou en Chine.

Mon premier voyage en Chine remonte à 1979, mais à cette époque, à cause des relations politiques tendues avec le Japon, la circulation dans le pays était encore limitée. Cependant, dès mes premiers pas sur le continent chinois, j'ai été profondément touché par le poids de l'histoire et l'immensité de l'espace.

Vers le milieu du $\mathrm{vI}^{\prime \prime}$ siècle, le bouddhisme a été introduit au Japon, via la péninsule Coréenne. Puis, aux VII"-VIII" siècles, ce sont cette fois les ambassades officielles japonaises envoyées dans la Chine des Tang qui ont permis l'assimilation du bouddhisme et, de manière plus générale, de la culture continentale. $\Lambda$ u VIII" siècle, la Chine des Tang était, au coeur de l'Asie orientale, à son apogée culturelle. La culture de la Chine des Tang, sur la base de l'héritage des Han, était alors vraiment universelle. Elle avait intégré à la fois la culture bouddhique venue de l'Inde et d'autres cultures étrangères comme celles des oasis de l'Asie centrale ou de la Perse sassanide. Elle avait également subi l'influence du Moyen-Orient et de la culture hellénique.

Le Japon de l'époque de Nara eut la chance extraordinaire de recevoir tous ces éléments continentaux.

Avant l'introduction du bouddhisme, le Japon insulaire possédait certes une culture propre, mais c'est l'apport de la culture continentale qui lui permit d'entrer en contact avec l' $\Lambda$ sie orientale et de se forger une conscience nationale.

Le Japon a créé une nouvelle culture par le mélange entre les cultures indigène et continentale, et il nous faut prendre en compte ces deux aspects lorsque l'on envisage la nature véritable de la civilisation japonaise. En parcourant les sites de la Route de la Soie, axe d'échange entre l'Occident et l'Orient, je n'ai cessé de penser qu'il était difficile de saisir la nature véritable de notre civilisation sans replacer le Japon dans le contexte de ses relations avec le reste du monde et avec l'Asie orientale en particulier. Lorsque l'on examine les trésors conservés au Shôsô-in à Nara, 
qui ont été apportés du continent au VIIr" siècle, on comprend combien la culture chinoise des Tang s'est formée sous l'influence des cultures de l'Asie occidentale, de l'Asie centrale et de I'Inde. Tous ces objets d'art décoratif venus du continent ont été précieusement conservés jusqu'à aujourd'hui. Certains sont identiques aux objets découverts à l'occasion de fouilles en Chine ou dans les sites historiques de la Route de la Soie, mais, bien que leur technique de fabrication ou leur forme soient semblables, leur " présence " est très différente. Parmi ces trésors du Shôsô-in figurent des instruments de musique chinois de l'époque des Tang, des céramiques persanes à glaçure trois couleurs (sansai), des lissus provenant des oasis de l'Asie centrale, ainsi que des objets variés de l'Asie du Sud-Est et de l'Inde. Au monastère Tôdai-ji de Nara, édifié au VIII" siècle, on continue de pratiquer depuis plus d'un millénaire les cérémonies religieuses et les danses masquées dites de bugaku qui, dans leur pays d'origine, ont depuis longtemps disparu.

Parmi les pays d'influence bouddhique que j'ai eu l'opportunité de visiter, il faut citer la Chine, l'Ouzbékistan, le Kazakhstan, l'Afghanistan, le Népal, le Pakistan, l'Inde, le Sri I,anka, la Birmanie et la péninsule Indochinoise. Chacun de ces pays présente des aspects différents de part ses oasis, ses déserts, ses steppes ou ses voies d'accès maritimes - et des vestiges propres. En allant plus encore vers l'ouest on passe à l'Iran, à l'Irak, à la Syrie, à la Turquie, au Liban, à la péninsule Arabique, à l'Égypte et l'on arrive finalement à la Girèce puis à Rome. Lorsque l'on remonte aux origines de la culture orientale, on s'aperçoit que la culture du Moyen- et du Proche-()rient s'est étendue à l'Europe et s'est répandue de manière très large sur tout le continent eurasialique.

J'en veux pour preuve que les piliers du monastère Ilôryû-ji, édifié à Nara an vil" siècle la plus ancienne architecture en bois conservée de part le monde , offrent des ressemblances avec les colonnes renflées au liers de leur hauteur (entases) des temples grecs. De même, les peintures murales à thème bouddhique qui ornaient le pavillon principal (Kondôj de ce monastère présentaient des dessins qui rappellent le motif décoratif composé de rangées de perles, issu de la culture de la Perse sassanide.

Au cours de mes cent el quelques visites des sites historiques de la Route de la Soie, jai constalé avec regret les destructions et les disparitions dues aux guerres, aux catastrophes naturelles et aux pillages. Ces sites ne sont pas seulement la propriété des pavs qui les abritent, ils constituent aussi le précieux patrimoine de lhumanitć tout entière. 


\section{COMPTES RENDISS DE I'ACADÉMIE DES INSCRIPTIONS}

L'UNESCO a assuré la reconstruction et la protection de nombreux sites, comme les temples d'Abu Simbel en Égypte, de Borobudur en Indonésie ou de Polonnâruwa au Sri Lanka

Pour ma part, j’ai lancé l'idée d'une Croix-Rouge du patrimoine, en vue de sauver les sites culturels. L'esprit de cette entreprise est le même que celui de la Croix-Rouge humanitaire fondée en Suisse il y a plus d'un siècle, dans le sens où je considère que les vestiges culturels doivent être étudiés et conservés au-delà des questions de nationalité, de race ou d'époque.

D'autre part, je pense qu il ne faut pas seulement traiter les sites historiques dans leur dimension matérielle. Ils doivent aussi servir aux peuples meurtris par les guerres et souffrant de la misère à recouvrer leur fierté au travers de leur héritage culturel. Je suis persuadé qu'en prenant conscience de la dimension humaine de ces sites, ces peuples pourront se relever et, par leur propres forces, travailler à la reconstruction de leur pays. C'est à cette fin que j'ai proposé les moyens d'une collaboration économique et technique. Depuis dix ans, j'ai ceuvré à cette collaboration internationale, en tant qu'ambassadeur de bonne volonté de l'L'NESCO. La première réalisation concrète de cette entreprise a été la conservation des grottes bouddhiques de Dunhuang en Chine. Depuis plus d'une dizaine d'années je collabore de manière continue avec l'Institut national de Recherche sur Dunhuang, et j'ai réussi à obtenir du gouvernement japonais l'attribution d'un fonds pour le développement (ODA), qui a rendu possible la construction sur place d'un site d'exposition et d'un centre de recherche. Concernant la formation des chercheurs et des techniciens, ce fonds a permis à une cinquantaine de spécialistes, dans les domaines de l'archéologie, des sciences et de la restauration, de venir étudier au Japon, afin de se former à la recherche et. aux techniques de conservation. Au cours de ces dix années une aide a également été apportée sous la forme de fourniture de matériel pour la recherche. Grâce à ce programme, je peux affirmer qu'aujourd'hui l'Institut national de Recherche sur Dunhuang possède le meilleur niveau de qualification en Chine, et même au niveau international, pour la restauration des peintures murales des grottes bouddhiques.

Je voudrais terminer cette note d'information en revenant sur mon ceuvre de peintre. Actuellement, je travaille, pour le monastère Yakushi-ji de Nara, à la réalisation d'une série de peintures murales, inspirées du Mémoire sur les contrées occidentales à l'époque des Grands Tang (Da-Tang xiyu-ji), écrit par un disciple de Xuanzang en 646, qui doivent être achevées pour la fin de ce siècle. J'ai l'intention de les présenter au public le $1^{\text {rr }}$ janvier de l'an 2001. 
Cela fait une trentaine d'années que je me consacre à ce projet. Celle ceuvre représente le long voyage qu'entreprit en lnde le moine chinois de l'époque des Tang, Xuanzang, de 629 à 645, pour y recueillir les textes sacrés et l'enseignement du bouddhisme. Pour réunir les matériaux nécessaires à ces peintures, je me suis rendu, grâce à une autorisation spéciale du gouvernement chinois, dans la province autonome du Xinjiang, dont l'accès était alors strictement réservé. J'ai visité à de nombreuses reprises, dans le. même but, les antiques cilés des oasis du désert de Taklamakan: Turfan, Koutcha, Aysu, Kachgar, Yarkand, Khotan, Niya, Tchertchen ou encore Loulan. Dans ces différentes villes, par lesquelles passa le moine Xuanzang, se trouvent des sites qui témoignent de l'expansion du bouddhisme, à l'époque où la Route de la Soie était à sa plus haute prospérité.

J'ai tenté, dans la mesure du possible, de refaire le chemin parcouru par ce moine. Sur les hauts plateaux du Pamir au froid rigoureux, comme dans le désert torride de Taklamakan, j'ai vécu sous la tente pour pouvoir travailler sur le molif. J'ai eu en outre la chance de me rendre sur le site de Loulan, qui n'avait pas reçu la visite d'un étranger depuis le passage du célèbre archéologue anglais $\Lambda$ urel Stein, quelques soixante-dix ans plus tôt. Lors de mon second séjour à Loulan, j'ai passé trois jours et deux nuits sous la tente, afin de réaliser des dessins sur le vif. Loulan, abandonnée depuis le vil" siècle est tombée en ruines. I'ancienne cité, en plein coeur d'un désert où l'on ne trouve pas la moindre goutte d'eau, est interdite d'accès 200 kilomètres à la ronde. Des rares vestiges d'habitations qui subsistent, certaines encore munies de leurs portes, il nous semble cependant que pourraient surgir, si on les appelait, les maîtres des lieux. Et pourtant, il y a plus d'un millier d'années que ce site a été déserté par l'homme. l'archéologie, qui s'est développée au Nix" siècle, a permis de redonner vie à des périodes oubliées de l'histoire. Le musée du Louvre ou le British Museum présentent en permanence au public, par delà les siècles, ces témoignages de l'héritage culturel de l'humanité. Ils contribuent de cette manière à conserver et à donner un sens à ce patrimoine culturel.

Pour terminer, je voudrais émettre un souhait : que le xxr siècle nous permette cette fois, grâce à la collaboration internationale, de conserver et d'étudier sur place le patrimoine culturel, soumis sa et là à des menaces diverses.

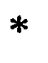


1140 COMPTES RENDUS DE L'ACADEMIE DES INSCRIPTIONS

MM. Jean LeClaAt, Jean-François JaRRIGE, M"' Colette CAIL,AAT, MM. Pierre AMANDRY et Robert TurCAN, ainsi que M. Azedine BESCHAOUCH, associé étranger, interviennent après cette note d'information. 